\title{
Ultrafast synthesis and sintering of materials in a single running experiment approach by using electric fields
}

\author{
Lílian M. JESUS ${ }^{a, \#}$, Ronaldo S. SILVA ${ }^{b}$, Jean-Claude M’PEKO $^{a,{ }^{*}}$ \\ ${ }^{a}$ São Carlos Institute of Physics, University of São Paulo (USP), P.O. Box: 369, CEP: 13560-970 São Carlos, SP, Brazil \\ ${ }^{b}$ Group of Advanced Ceramic Materials, Department of Physics, Federal University of \\ Sergipe (UFS), CEP: 49100-000 São Cristóvão, SE, Brazil
}

Received: October 16, 2018; Revised: December 21, 2018; Accepted: December 26, 2018

(c) The Author(s) 2019.

\begin{abstract}
Processing of materials in the form of ceramics normally involves several steps including calcination at a relatively low temperature for synthesis of the end-product powder and sintering at a high temperature for densification. The work we have been developing introduces a novel approach enabling synthesis plus sintering of materials in a single running experiment by using electric fields, ending with dense ceramics that display grains noticeably finer than in conventional processing. This new paradigm is fully illustrated with experiments conducted on amorphous $\mathrm{CaCu}_{3} \mathrm{Ti}_{4} \mathrm{O}_{12}$ precursor powder, shown to experience, on heating, crystallization through intermediate phases, followed by chemical reaction leading to synthesis of the end-product powder, plus densification depending on field adjustment. The processing time and furnace temperature are considerably reduced, demonstrating that enhanced synthesis and sintering rates applied under field input. Similar results found in $\mathrm{Bi}_{2 / 3} \mathrm{Cu}_{3} \mathrm{Ti}_{4} \mathrm{O}_{12}$ are also shown. The different factors that may contribute to this unique scenario, including Joule heating, defect generation, and reduction of free energy for nuclei formation promoted by the applied field, are briefly discussed. Overall, the findings we bring here are exclusive as they show an exploitable way that allows rapid processing of materials with good control over particle and grain coarsening.
\end{abstract}

Keywords: field-assisted processing; synthesis; sintering; microstructure; dielectric response

\section{Introduction}

Functional dielectric materials have been the subject of continuous research over the last century, and are the active elements in common electro-electronic devices such as capacitors, gas sensors, actuators, thermistors, and varistors [1-4], frequently in the form of ceramics.

\# Present address: Department of Physics, Federal University of São Carlos (UFSCar), 13560-905 São Carlos, SP, Brazil.

* Corresponding author.

E-mail: peko@ifsc.usp.br, jcpeko@yahoo.com
The properties of such materials are highly sensitive towards structural and microstructural characteristics that need to be optimized depending on the applications envisaged. Processing of ceramics involves several steps that comprise calcination of the precursor materials at a relatively low but high enough temperature to synthesize the end-product powder of interest, followed by grinding to reduce particle size, compaction to get a reasonable green density (better if scaling above $50 \%$ of the theoretical density), and finally sintering of the pressed body at a high temperature for densification. Challenges in this topic 
include low-cost processing, densification maximization, and grain growth minimization, the latter determining the current trend in device miniaturization for microelectronics. Nevertheless, controlling competition between densification and grain coarsening is extremely difficult because the driving forces for both are proportional to the reciprocal of grain size and, hence, comparable in magnitude $[5,6]$.

Successful approaches so far developed for materialisation of this (densification versus grain coarsening) control purpose include hot pressing (HP), sinter forging (SF), spark plasma (SPS), and two-step sintering (TSS) [1,4,5,7-11]. One should note, however, that most of these techniques bring with them non-negligible to high setup and/or processing costs. In HP and SPS, for instance, dense and fine-grained ceramics are produced at relatively low temperatures while subjecting the sintering bodies to relatively high pressures. These are two procedures somewhat costly (setup viewpoint), besides verification that the application of pressures above several hundreds of $\mathrm{MPa}$ during sintering may modify the final structural characteristics and dielectric properties of a processed material $[12,13]$. This makes pressureless sintering methods much more attractive in ceramics processing. An example is TSS where fine-grained bodies can be produced in air at relatively low temperatures, but at the expense of requiring, unfortunately, annealing time as high as $10-30 \mathrm{~h}$ to get high-density materials. This makes the technique also not too attractive for production of ceramics, especially at industrial scale. Regarding synthesis and sintering of materials, in summary, investigating new approaches that might traduce into lower processing costs is a topic of permanent interest.

For development of the present work, inspiration came from the alternative pressureless method recently introduced in the literature [14], called flash sintering, which is based on applying an electric field across the sintering body during thermal treatment. This approach has shown to enable production of high-density ceramics in a matter of seconds, at furnace temperatures well below those required in conventional sintering. Examples of successful application of this novel method include dissimilar materials like $\mathrm{Y}_{2} \mathrm{O}_{3}$-doped $\mathrm{ZrO}_{2}[14,15]$, $\mathrm{Co}_{2} \mathrm{MnO}_{4}$ [16], MgO-doped $\mathrm{Al}_{2} \mathrm{O}_{3}$ [17], Gd-doped $\mathrm{BaCeO}_{3}$ [18], and $\mathrm{CeO}_{2}$ [19], $\mathrm{BaTiO}_{3}$ [20], $\mathrm{TiO}_{2}$ [21], $\mathrm{CaCu}_{3} \mathrm{Ti}_{4} \mathrm{O}_{12}$ [22], and $\mathrm{MgTiO}_{3}$ [23] electroceramics. In particular, perovskite-structured $\mathrm{CaCu}_{3} \mathrm{Ti}_{4} \mathrm{O}_{12}$ (CCTO) ceramics, targeted in this work, have in recent years drawn considerable attention as they show a giant dielectric constant $\left(K_{\text {real }}\right)$ and remarkable nonlinear current-voltage response [24-28], making them potential materials for application in super high- $K_{\text {real }}$ capacitors and high-efficiency switching and gas-sensing devices. In terms of processing, conventional synthesis (solid-state reaction) and sintering of CCTO are most frequently achieved at temperatures of 1000 and $1100{ }^{\circ} \mathrm{C}$, respectively, for dwell time of several hours $[24,26,29,30]$. Thermal cycling of this material under field input was recently shown to reduce considerably these sintering (time and furnace temperature) parameters [22].

Different from all previous works on flash sintering, here we considered using electric fields for ultrafast production of high-quality CCTO electroceramics starting from amorphous precursor powder. We show that this can be made into a high-density ceramic in a single experiment approach at time and furnace temperatures drastically reduced, demonstrating that enhanced synthesis and sintering rates apply under field input. The effects from both electric field and current strengths across the processed bodies during thermal cycling are presented and discussed. Regarding exploration of this approach in other materials, an example of data on $\mathrm{Bi}_{2 / 3} \mathrm{Cu}_{3} \mathrm{Ti}_{4} \mathrm{O}_{12}$ is also provided in this report, as Electronic Supplementary Material (ESM).

\section{Experimental procedure}

Preparation of the $\mathrm{CaCu}_{3} \mathrm{Ti}_{4} \mathrm{O}_{12}$ precursor powder was based on the Pechini chemical method [31,32]. In summary, calcium, copper, and titanium citrates were separately prepared using calcium carbonate $\left(\mathrm{CaCO}_{3}\right.$, Synth, 99\%), copper nitrate $\left(\mathrm{Cu}\left(\mathrm{NO}_{3}\right)_{2} \cdot 3 \mathrm{H}_{2} \mathrm{O}\right.$, Labsynth, $98 \%$ ), and titanium isopropoxide $\left(\mathrm{Ti}\left[\mathrm{OCH}\left(\mathrm{CH}_{3}\right)_{2}\right]_{4}\right.$, Alfa Aesar, 97\%) mixed in stoichiometric amounts with citric acid (CA), previously dissolved in distilled water $\left(0.1 \mathrm{~g} \cdot \mathrm{mL}^{-1}\right)$, at the molar ratios of $1: 3(\mathrm{Ca}: \mathrm{CA})$ for calcium and 1:6 (Cu, Ti:CA) for copper as well as titanium. Ethylene glycol (EG) was then added to these solutions, at the mass ratio of $\mathrm{CA}: \mathrm{EG}=60: 40$, to promote citrate polymerization by polyesterification. The $(\mathrm{Ca}, \mathrm{Cu}, \mathrm{Ti})$-containing resin was prepared by mixing these polyesters, followed by $\mathrm{pH}$ adjustment to 9 by adding ammonium hydroxide. A stable resin with a blue colour and transparent appearance was then obtained, and heated to $120{ }^{\circ} \mathrm{C}$ to eliminate excess water. This chemically-prepared resin was then heated 
to $400{ }^{\circ} \mathrm{C}$, followed by annealing for $2 \mathrm{~h}$ to remove most organic compounds, ending with amorphous starting powder as will be shown later.

The powder was then cold-pressed at $280 \mathrm{MPa}$ into dog bone-like shaped samples, as shown in Fig. 1(a); the black-like colour comes from presence of residual organic compounds. Processing of the samples was conducted in a molybdenum di-silicide furnace at a heating rate of $10{ }^{\circ} \mathrm{C} \cdot \mathrm{min}^{-1}$, with and without an applied electric field $(E)$ as described in Ref. [17]. $E$ was varied from low values to $240 \mathrm{~V} \cdot \mathrm{cm}^{-1}$, in the direct current (DC) mode, while a preset maximum current flowing across the processed sample was imposed, with values ranging from 5.0 to $42.0 \mathrm{~mA} \cdot \mathrm{mm}^{-2}$. A Sorensen 300-2 DC power supply was used in these experiments, and the current was measured with a digital Keithely 2000 multimeter. All the experiments were ended $1 \mathrm{~min}$ after observation of the flash processing (synthesis or sintering) events presented in this report. For an appropriate comparison, an identical holding time of $1 \mathrm{~min}$ was considered for conventional processing $(E=0)$, finally conducted here at a verified temperature of $1030{ }^{\circ} \mathrm{C}$. Besides using a thermocouple positioned near the sample, temperature of the processing body was in various representative cases also monitored by a CLTM-1 Micro-Epsilon optical pyrometer, assuming a specimen emissivity of 0.9 (supposed to be a valid approximation for most oxide ceramics). Shrinkage of the specimens was monitored
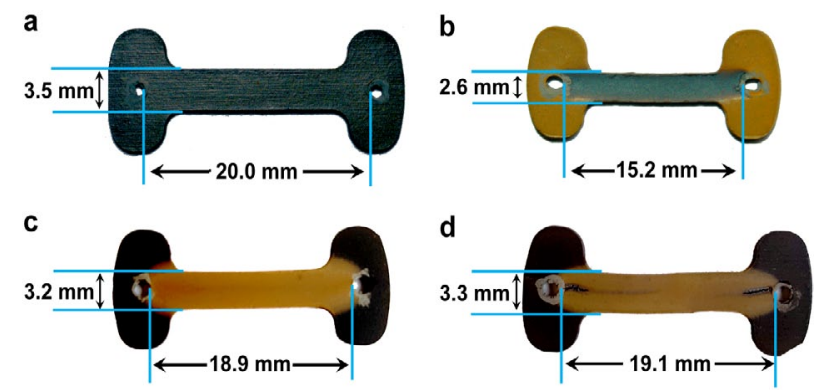

Fig. 1 Optical view of dog bone-shaped samples (a) after uniaxial cold-pressing (at $280 \mathrm{MPa}$ ) of the initial precursor heat treated at $400{ }^{\circ} \mathrm{C}$ for $2 \mathrm{~h}$, (b) after sintering under an applied field of $30 \mathrm{~V} \cdot \mathrm{cm}^{-1}$, (c) showing a homogeneous body after flash under $160 \mathrm{~V} \cdot \mathrm{cm}^{-1}$ at $J=$ $22.0 \mathrm{~mA} \cdot \mathrm{mm}^{-2}$, and (d) with channelling-like physical damage after flash under $160 \mathrm{~V} \cdot \mathrm{cm}^{-1}$ now at $J=$ $25.0 \mathrm{~mA} \cdot \mathrm{mm}^{-2}$. The black-like colour in (a), (c), and (d) comes from presence of residual organic compounds, turning to be yellowgreen-like in (a) to (d) after removal. As normally expected, the sample in (b) was gray-like towards the sintered dog bone gage section. with an Imaging DMK23U445 CCD camera, while the final density was estimated by the Archimedes method.

Phase development during thermal cycling of the material under field action was analysed by X-ray diffraction (XRD). That is, material processing was stopped at selected instances, after which XRD measurements were conducted at room temperature, using a Phillips X'Pert MPD equipment, operating with $\mathrm{Cu} \mathrm{K} \alpha$ radiation in continuous mode, with $2 \theta$ varying from $20^{\circ}$ to $80^{\circ}$, in step of $0.02^{\circ}$. A set of samples was sputter coated with carbon, and had their microstructures imaged towards the central region of the dog bone length using an FEI Inspect F50 scanning electron microscope (SEM). The images were used to estimate the average particle (in powder) and grain (in ceramics) sizes by applying the linear intercept method [33]. Imaging both as-sintered and fracture (cross section) surfaces was in this work considered. The complex dielectric constant $K^{*}\left(\equiv K_{\text {real }}-\mathrm{j} \cdot K_{\text {imag }}\right)$, where $K_{\text {real }}$ and $K_{\text {imag }}$ refer to the real and imaginary parts, respectively, was measured at room temperature, using a Solartron SI 1260 impedance analyser, from which the dielectric losses were also evaluated using $\tan \delta=$ $K_{\text {imag }} / K_{\text {real }}$. These measurements were carried out on powder (with comparable volume fraction of porosity after compaction) as well as on sintered samples, towards the $10 \mathrm{~Hz}$ to $100 \mathrm{kHz}$ frequency range where no material-electrode polarization contribution was verified [34].

Finally, the ESM provided in this report includes electric current and XRD data from the parent $\mathrm{Bi}_{2 / 3} \mathrm{Cu}_{3} \mathrm{Ti}_{4} \mathrm{O}_{12}$ compound processed under field input. The precursor powder was synthesized following the identical Pechini preparation protocol, as reported in Ref. [32] and summarized above, except for the use of $\mathrm{Bi}_{2} \mathrm{O}_{3}$ in place of $\mathrm{CaCO}_{3}$ as starting raw material.

\section{Results and discussion}

Figure 2(a) shows representative curves of current density $(J)$ against furnace temperature (see full data given in Figs. S1(a) and S1(b) in the ESM), as measured during heat treatment of the precursor CCTO powder towards a wide range of temperatures, under electric field action. These data reveal a complex behaviour that is carefully analysed in the following. For $0<E \leqslant 40 \mathrm{~V} \cdot \mathrm{cm}^{-1}, J$ shows a shoulder around $700{ }^{\circ} \mathrm{C}$, followed by an abrupt rise towards the last stage of heat treatment where the maximum current 
density preset to $J=42.0 \mathrm{~mA} \cdot \mathrm{mm}^{-2}$ was reached. For $E \geqslant 60 \mathrm{~V} \cdot \mathrm{cm}^{-1}$, the curves are qualitatively similar, except for no occurrence of the shoulder. The data towards lower temperatures are magnified in the figure inset, noting the incidence of an additional "anomaly" that manifests as a broad $J$ peak. Figure 2(b) depicts the thermal behaviour of the corresponding true linear strain, defined as

$$
\in=\ln \left(\frac{L}{L_{0}}\right)
$$

where $L$ is the sample length and $L_{0}(=2.0 \mathrm{~cm})$ its initial value. This reveals significant to high specimen shrinkage for $E \leqslant 40 \mathrm{~V} \cdot \mathrm{cm}^{-1}$, and practically no shrinkage for $E \geqslant 60 \mathrm{~V} \cdot \mathrm{cm}^{-1}$. Figure 1(b) is a view of a sample after processing under, e.g., $E=30 \mathrm{~V} \cdot \mathrm{cm}^{-1}$, suggesting homogeneous sintering towards the dog bone gage section where the field was applied during heat treatment. The specimen is gray-like towards the sintered gage section, and yellowgreen-like where there was no applied field and the low furnace temperature was enough to promote organic compounds removal, but not sintering. For isotropic shrinkage, as we found in this work to a good approximation (Fig. 1), the resulting density and strain ( $\rho$ and $\in$ ) theoretically satisfy:

$$
\ln \left(\frac{\rho}{\rho_{0}}\right)=3|\in|
$$

where $\rho_{0}$ is the green density (about $2.02 \mathrm{~g} \cdot \mathrm{cm}^{-3}$ in this work). Final values of density $\left(\rho_{\text {rel }}\right)$, relative to the theoretical density of CCTO $\left(\mathrm{TD}=5.05 \mathrm{~g} \cdot \mathrm{cm}^{-3}\right)$ [35], were $92 \%$ to $98 \% \mathrm{TD}$ for $10 \mathrm{~V} \cdot \mathrm{cm}^{-1} \leqslant E \leqslant$ $40 \mathrm{~V} \cdot \mathrm{cm}^{-1}, 77 \%$ TD for zero-field processing, and $46 \%$ TD (in average) for $60 \mathrm{~V} \cdot \mathrm{cm}^{-1} \leqslant E \leqslant 240 \mathrm{~V} \cdot \mathrm{cm}^{-1}$, as estimated via Archimedes method. For the former (sintered materials), the values of $\rho_{\text {rel }}$ are listed in Table 1.

In terms of processing parameters, the following observation should be made at this instant. Towards high fields $\left(E \geqslant 60 \mathrm{~V} \cdot \mathrm{cm}^{-1}\right)$, imposing maximum $J$ values above $22.0 \mathrm{~mA} \cdot \mathrm{mm}^{-2}$ only led from current localization to channelling-like physical damage along the sample length rather than densification. This is registered in Fig. 1(d) for $E=160 \mathrm{~V} \cdot \mathrm{cm}^{-1}$ with $J=$ $25.0 \mathrm{~mA} \cdot \mathrm{mm}^{-2}$ at flash, versus Fig. 1(c) where a homogeneous body is still observed after flash at $J=$ $22.0 \mathrm{~mA} \cdot \mathrm{mm}^{-2}$ (a kind of upper bound current for safe flash). In both cases the samples are yellowgreen-like

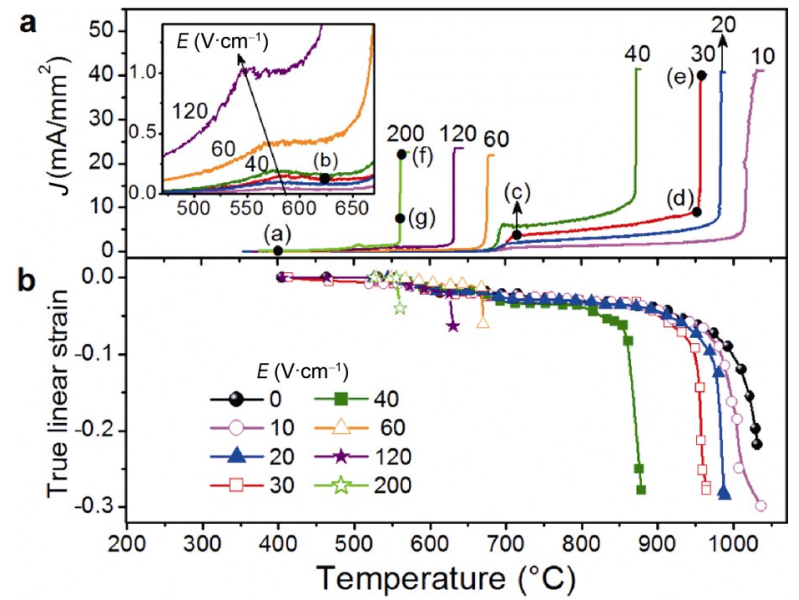

Fig. 2 Temperature dependence of (a) current density $(J)$ and (b) true linear shrinkage during CCTO processing under electric field $(E)$ input. The current density limits were $J=42.0 \mathrm{~mA} \cdot \mathrm{mm}^{-2}$ for $10 \mathrm{~V} \cdot \mathrm{cm}^{-1} \leqslant E \leqslant$ $40 \mathrm{~V} \cdot \mathrm{cm}^{-1}$ and $J=22.0 \mathrm{~mA} \cdot \mathrm{mm}^{-2}$ for $E \geqslant 60 \mathrm{~V} \cdot \mathrm{cm}^{-1}$. Inset in (a): magnification of the current data towards lower temperatures. The indicated points (a) to (g) represent different instants during material processing (and are discussed in the text).

Table 1 Applied electric field $(E)$, relative density $\left(\rho_{\text {rel }}\right)$, furnace ( $T_{\text {furn }}^{\mathrm{O3S}}$ ) and pyrometer ( $T_{\mathrm{pyro}}^{\mathrm{O3S}}$ ) temperatures measured at flash (while allowing the imposed maximum current across the sample to last 1 min before turning off the power supply), and average grain size (AGS)

\begin{tabular}{ccccc}
\hline$E(\mathrm{~V} / \mathrm{cm})$ & $\rho_{\text {rel }}(\% \pm 1 \%)$ & $T_{\text {furn }}^{\text {O3S }}\left({ }^{\circ} \mathrm{C}\right)$ & $T_{\text {pyro }}^{\text {O3S }}\left({ }^{\circ} \mathrm{C}\right)$ & AGS $(\mathrm{nm})$ \\
\hline $0^{\dagger}$ & 77 & - & - & $630 \pm 180$ \\
10 & 98 & 1015 & 1075 & $880 \pm 175$ \\
15 & 96 & 1005 & 1085 & $740 \pm 170$ \\
20 & 94 & 983 & 1075 & $740 \pm 175$ \\
30 & 92 & 955 & 1037 & $560 \pm 200$ \\
35 & 94 & 908 & 1020 & $550 \pm 210$ \\
40 & 92 & 870 & 1018 & $530 \pm 170$ \\
\hline
\end{tabular}

${ }^{\dagger}$ Heating process for sintering was in this conventional case stopped at $1030{ }^{\circ} \mathrm{C}$, followed by annealing for also $1 \mathrm{~min}$.

towards the gage section due to removal of the organic compounds. The observation above also applied for processing towards low fields $\left(E \leqslant 40 \mathrm{~V} \cdot \mathrm{cm}^{-1}\right)$ where imposing $J$ values higher than $42.0 \mathrm{~mA} \cdot \mathrm{mm}^{-2}$ led to identical channelling-like damage effect along the densified bulk, as also observed elsewhere in flash sintering of, e.g., Gd-doped $\mathrm{BaCeO}_{3}[18]$ and $\mathrm{BaTiO}_{3}$ [20].

Notice in Fig. 2 that the entire $J$ and $\in$ curves shift towards lower furnace temperatures as $E$ is increased, meaning field-enhanced kinetics of the processes 
involved, including occurrence of densification. The points (a) to (g) indicated in Fig. 2(a) refer to representative instances where the experiments were stopped and X-ray diffraction analyses conducted at room temperature, the patterns of which are shown in Fig. 3. At point (a), as we mentioned above, the starting Pechini-derived product is amorphous. Taking material processing under, e.g., $E=30 \mathrm{~V} \cdot \mathrm{cm}^{-1}$ as a reference, we chose to conduct the structural analyses at points (b) to (e). The data at point (b) show presence of $\mathrm{CuO}$ (ICSD 67850) and $\mathrm{TiO}_{2}$ (ICSD 200392), besides trace of CCTO (ICSD 32002). At point (c) a single CCTO phase is finally synthesized (the Miller $h k l$ index numbers are indicated between parentheses). While talking in this case about synthesizing CCTO at a furnace temperature of $713{ }^{\circ} \mathrm{C}$ for virtually zero annealing time, in zero-field approach this Pechini-derived precursor powder would have needed to be heat treated for $2 \mathrm{~h}$ at about $800{ }^{\circ} \mathrm{C}$ to get a second phase-free CCTO powder [32]. At points (d) and (e) incidence of a single CCTO phase is also verified. The same observation applies for points (f) and (g) corresponding now to processing under, e.g., $E=200 \mathrm{~V} \cdot \mathrm{cm}^{-1}$.

The results illustrated in Figs. 2 and 3 allow drawing the following important conclusions. For $10 \mathrm{~V} \cdot \mathrm{cm}^{-1} \leqslant$ $E \leqslant 40 \mathrm{~V} \cdot \mathrm{cm}^{-1}$, on the one hand, the powder

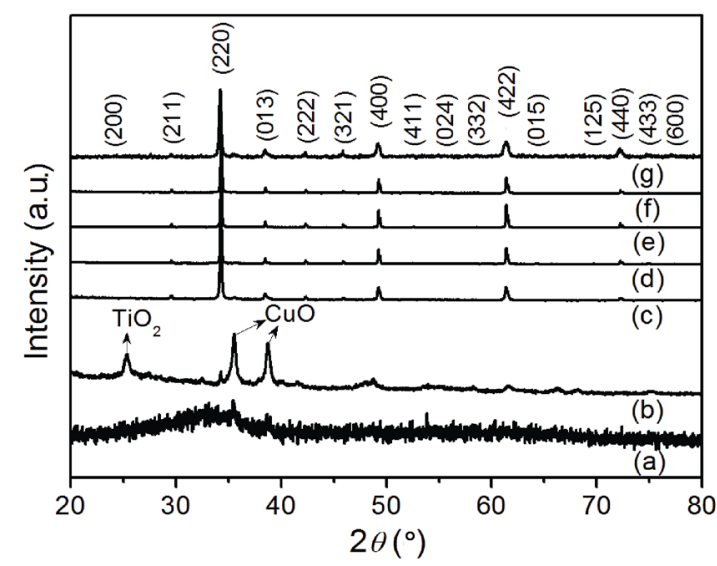

Fig. 3 X-ray diffraction patterns corresponding to the points (a) to (g) indicated in Fig. 2(a). Point (a) is related to the powder initially heat treated at $400{ }^{\circ} \mathrm{C}$ for $2 \mathrm{~h}$. Points (b)-(e) are connected with the samples at furnace temperatures of (b) $625{ }^{\circ} \mathrm{C}$, (c) $713{ }^{\circ} \mathrm{C}$, (d) $950{ }^{\circ} \mathrm{C}$, and (e) $955{ }^{\circ} \mathrm{C}$ during processing under $E=30 \mathrm{~V} \cdot \mathrm{cm}^{-1}$ (current density limit of $J=42.0 \mathrm{~mA} \cdot \mathrm{mm}^{-2}$ in the last case). Points (f) and (g) are related to the samples at a furnace temperature of $562{ }^{\circ} \mathrm{C}$ during processing under $E$ $=200 \mathrm{~V} \cdot \mathrm{cm}^{-1}$ with a current density limit of $J=22.0$ and $5.0 \mathrm{~mA} \cdot \mathrm{mm}^{-2}$, respectively. transits from amorphous to crystallization through intermediate phases, followed by CCTO synthesis, and then sintering with good densification: this is the fast one-step synthesis plus sintering $(\mathrm{O} 3 \mathrm{~S})$ of materials we introduce here, starting from amorphous precursor powder. This ends with the so-called flash sintering event recently presented in the literature [8,14-22], and characterized by a sudden rise in electric current and material densification (Fig. 2). The values of furnace temperature reached at flash $\left(T_{\text {furn }}^{\mathrm{O} S}\right)$ have also been listed in Table 1. At $E=40 \mathrm{~V} \cdot \mathrm{cm}^{-1}$, for instance, values of $T_{\text {furn }}^{\mathrm{O} 3 \mathrm{~S}}=870{ }^{\circ} \mathrm{C}$ and $\rho_{\mathrm{rel}}=92 \%$ TD (even considering only $1 \mathrm{~min}$ of annealing time) were found, while conventional sintering of solid-state prepared CCTO powder is most frequently conducted at $1100{ }^{\circ} \mathrm{C}$, for annealing time of several hours [24,26,29,30].

For $E \geqslant 60 \mathrm{~V} \cdot \mathrm{cm}^{-1}$, on the other hand, it is concluded from Figs. 2 and 3 that the powder drives to crystallization through intermediate phases and, then, instantaneous CCTO synthesis, without experiencing densification (even for $J>22.0 \mathrm{~mA} \cdot \mathrm{mm}^{-2}$, as we commented above): this we call flash synthesis (of the end-phase product), found to be here achievable at really low furnace temperatures, below $500{ }^{\circ} \mathrm{C}$ for $E>210 \mathrm{~V} \cdot \mathrm{cm}^{-1}$ (see Fig. S1(b) in the ESM). Indeed, we recently announced incidence of this unique phenomenon in Ref. [36]. To give a much more complete picture of processing scenario towards a wide range of applied electric fields, we chose to bring here a few but important representative data of this distinct phenomenon. This is because such data help understanding the stepwise evolution of the originally amorphous system to only synthesis or synthesis plus sintering depending on field strength. Considering again the results in Figs. 2(a) and 3 for $10 \mathrm{~V} \cdot \mathrm{cm}^{-1} \leqslant$ $E \leqslant 40 \mathrm{~V} \cdot \mathrm{cm}^{-1}$, finally, material processing until reaching the shoulder around $700{ }^{\circ} \mathrm{C}$ represents then what can be called by fast synthesis.

A direct and important observation deriving as well from Fig. 2 (supported by the data given in Fig. 3) is then the ability the electric field-assisted processing method shows here for easily detecting occurrence of physico-chemical processes like crystallization and chemical reactions during thermal cycling of the material. This capability is further reinforced by the results presented in the following. That is, Fig. 4 depicts the XRD and electric current data, for processing under, e.g., $15 \mathrm{~V} \cdot \mathrm{cm}^{-1}$, from Pechini-derived 
CCTO precursor powder initially heat treated for $2 \mathrm{~h}$ at $400{ }^{\circ} \mathrm{C}$ (amorphous powder) and $800{ }^{\circ} \mathrm{C}$ (single-phase powder). As an extension of applicability of this processing approach to other materials, the XRD and electric current data, collected under, e.g., $7.5 \mathrm{~V} \cdot \mathrm{cm}^{-1}$, from the parent $\mathrm{Bi}_{2 / 3} \mathrm{Cu}_{3} \mathrm{Ti}_{4} \mathrm{O}_{12}$ (BCTO) compound are depicted in the ESM (data given as Fig. S2 in the ESM). These data arose from Pechini-derived BCTO precursor powder initially heat treated for $2 \mathrm{~h}$ at $400{ }^{\circ} \mathrm{C}$ (showing to be partially-amorphous powder), $800{ }^{\circ} \mathrm{C}$ (multi-phase powder), and $900{ }^{\circ} \mathrm{C}$ (single-phase powder). Overall, irrespective of the considered material (CCTO or BCTO), the results presented in Figs. 2, S1(a) and S1(b) in the ESM, 3, 4, and S2 in the ESM reveal coherent characteristics that can be summarized as follows: (i) for originally amorphous powder, both "anomalies" associated with crystallization through intermediate phases (towards low temperatures) and chemical reaction-promoted synthesis of the end product (towards the intermediate temperatures) are observed; (ii) for starting powder containing intermediate phases (say, multi-phase powder), only the end-product synthesis-related anomaly is sensed; finally, (iii) when dealing with single-phase powder, neither of these two anomalies are detected, just as would be then expected. Towards the last stage of sintering at higher temperatures,
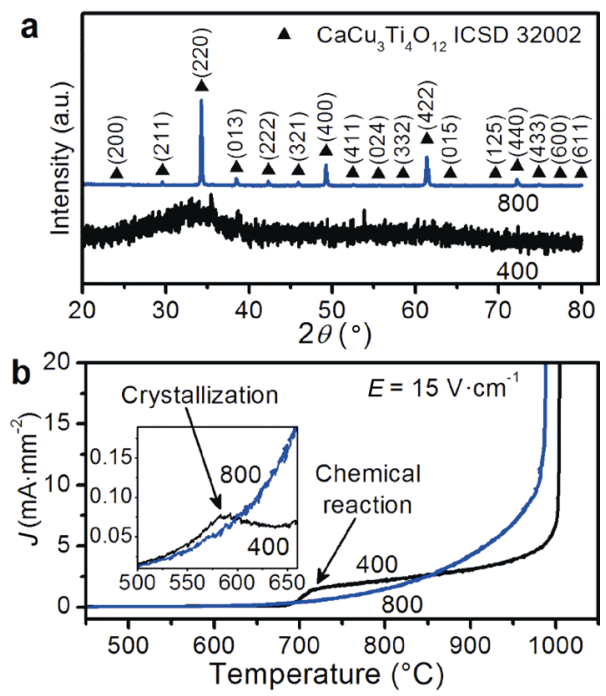

Fig. 4 (a) XRD patterns of the CCTO precursor powder after heat treatment at 400 and $800{ }^{\circ} \mathrm{C}$ for $2 \mathrm{~h}$. The powder is amorphous at $400{ }^{\circ} \mathrm{C}$, while a single CCTO phase is synthesized at $800{ }^{\circ} \mathrm{C}$; (b) temperature dependence of current density $(J)$ for the two powders during processing under a field of $15 \mathrm{~V} \cdot \mathrm{cm}^{-1}$. In the course of sintering, only the amorphous powder shows the anomalies related to crystallization and chemical reaction. all these specimens experienced instantaneous-like densification under low field input (Figs. 2, S1(a) in the ESM, 4, and S2 in the ESM).

Figure 5 shows representative micrographs from fracture surfaces (cross section view) of CCTO samples after sintering without and with an applied electric field. While the conventionally sintered specimen reveals porous $\left(E=0 \mathrm{~V} \cdot \mathrm{cm}^{-1}\right.$, and $\left.\rho=77 \% \mathrm{TD}\right)$, high densities were achieved for the samples processed under electric field. In addition, a trend of grain growth inhibition with increasing $E$ was observed in the dense specimens. For both particle and grain size evaluation, we found better to consider analysing images from the surfaces of the as-processed samples. Figure 6 illustrates such micrographs applying at some of the points indicated in Fig. 2(a): point (e) after flash sintering, point (c) after fast synthesis, and points (f) and (g) after flash synthesis. In general, all the imaged microstructures revealed quite homogeneous in particle and grain size distribution.

The estimated values of average grain size (AGS, in dense samples) and particle size (APS) are shown in Fig. 7; the AGS data (and corresponding distribution) have also been included in Table 1. AGS decreased with raising $E$, reaching a value as low as $530 \mathrm{~nm}$ for $E$ $=40 \mathrm{~V} \cdot \mathrm{cm}^{-1}$; just recalling that AGS in CCTO ceramics normally exceeds (well significantly in most cases) $1.0 \mu \mathrm{m}[29,30,32]$. In the course of fast one-step synthesis plus sintering (O3S), APS (Fig. 7 inset) at

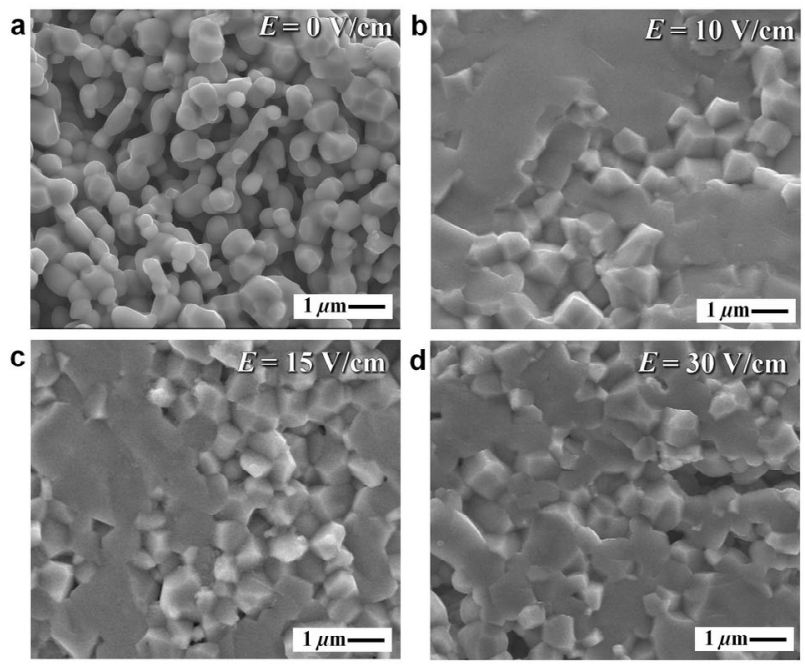

Fig. 5 Representative micrographs of the fracture surfaces (cross section) from CCTO specimens processed in this work. (a) Conventional sintering $\left(E=0 \mathrm{~V} \cdot \mathrm{cm}^{-1}\right)$; fast $\mathrm{O} 3 \mathrm{~S}$ processing under (b) $E=10 \mathrm{~V} \cdot \mathrm{cm}^{-1}$, (c) $E=15$ $\mathrm{V} \cdot \mathrm{cm}^{-1}$, and (d) $E=30 \mathrm{~V} \cdot \mathrm{cm}^{-1}$, with a current density limit of $J=42.0 \mathrm{~mA} \cdot \mathrm{mm}^{-2}$ and a dwell time of $1 \mathrm{~min}$. 


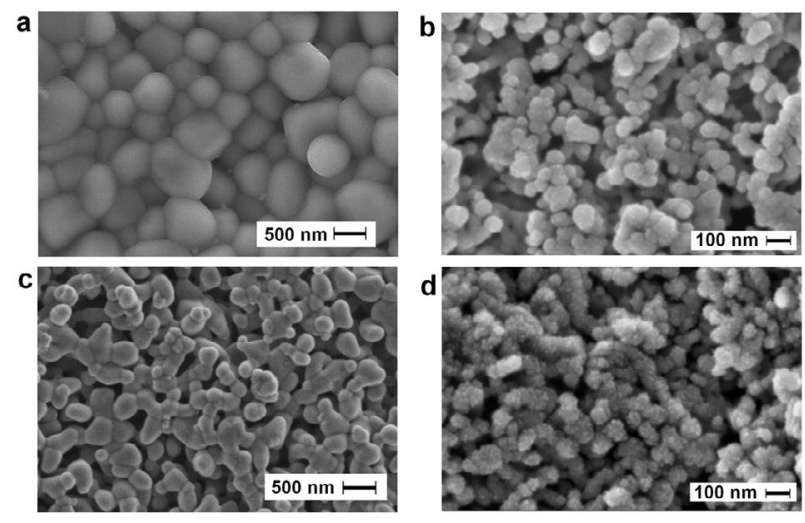

Fig. 6 Representative micrographs of CCTO specimens processed in this work. (a) Fast $\mathrm{O} 3 \mathrm{~S}$ processing under $E=30$ $\mathrm{V} \cdot \mathrm{cm}^{-1}$, with a current density limit of $J=42.0 \mathrm{~mA} \cdot \mathrm{mm}^{-2}$ (point (e) in Fig. 2(a)); (b) fast synthesis under $E=30 \mathrm{~V} \cdot \mathrm{cm}^{-1}$, at which instance the specimen reached a current density of $J=4.1$ $\mathrm{mA} \cdot \mathrm{mm}^{-2}$ (point (c) in Fig. 2(a)); (c) and (d) flash synthesis under $E=200 \mathrm{~V} \cdot \mathrm{cm}^{-1}$ for current density limits of $J=22.0$ and $7.5 \mathrm{~mA} \cdot \mathrm{mm}^{-2}$, respectively (points (f) and (g) in Fig. 2(a)). The dwell time at the current limits was $1 \mathrm{~min}$. The two last images (c) and (d) are reproduced with permission from Ref. [36], (C) The Royal Society of Chemistry 2016.

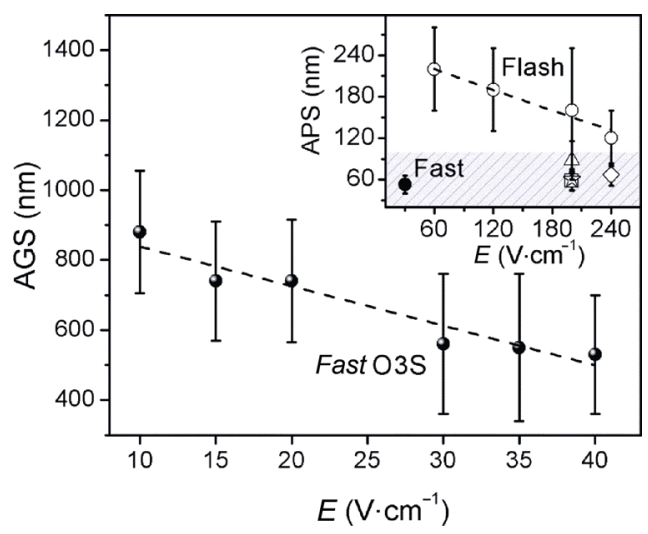

Fig. 7 Average grain size (AGS) after fast O3S processing of CCTO with the current density limit of $J=$ $42.0 \mathrm{~mA} \cdot \mathrm{m}^{-2}$. Inset: average particle size (APS) applying for fast CCTO synthesis (closed circle; specimen at point (c) in Fig. 2(a)), and flash CCTO synthesis for different fields with the current density limit of $J=22.0 \mathrm{~mA} \cdot \mathrm{mm}^{-2}$ (open circles); for $E=200 \mathrm{~V} \cdot \mathrm{cm}^{-1}$ with $J=10.0$ $\mathrm{mA} \cdot \mathrm{mm}^{-2}$ (open triangle), $J=7.5 \mathrm{~mA} \cdot \mathrm{mm}^{-2}$ (open star), and $J=5.0 \mathrm{~mA} \cdot \mathrm{mm}^{-2}$ (open square; specimen at point $(\mathrm{g}$ ), Fig. 2(a)); and finally for $E=240 \mathrm{~V} \cdot \mathrm{cm}^{-1}$ with $J=12$ $\mathrm{mA} \cdot \mathrm{mm}^{-2}$ (open diamond). The dashed lines are just a guide for eyes.

point (c), i.e., fast synthesis under $E=30 \mathrm{~V} \cdot \mathrm{cm}^{-1}$, is only $53 \mathrm{~nm}$ (closed circle). The value is $300 \mathrm{~nm}$ (5.7 times higher) after zero-field processing of identical Pechini-derived powder, proved to require heat treatment at $800{ }^{\circ} \mathrm{C}$ to successfully get a single-phase end product [32]. Similar results of optimal CCTO synthesis occurring towards relatively-high temperatures falling in the $700-800{ }^{\circ} \mathrm{C}$ range and final average particle size in the $200-400 \mathrm{~nm}$ range have been reported for CCTO powder processed through pyrolysis and combustion wet-chemistry methods [37,38]. Regarding flash synthesis, back to the inset of Fig. 7, APS also decreased with raising $E$, going from $220 \mathrm{~nm}$ at $E=60 \mathrm{~V} \cdot \mathrm{cm}^{-1}$ to $120 \mathrm{~nm}$ at $E=240 \mathrm{~V} \cdot \mathrm{cm}^{-1}$, with the maximum current preset to $J=22.0 \mathrm{~mA} \cdot \mathrm{mm}^{-2}$ (open circles). APS also fell down with decreasing this maximum current at flash: with $J$ limited to 5.0 $\mathrm{mA} \cdot \mathrm{mm}^{-2}$, for instance, APS $=58 \mathrm{~nm}$ for processing at $E=200 \mathrm{~V} \cdot \mathrm{cm}^{-1}$ (open square). Refer to the caption of Fig. 7 where all the considered processing conditions (and used symbols) are informed.

All these results, shown in Figs. 2, 3, 6, and 7, demonstrate that electric field can be used to effectively accelerate synthesis and sintering of materials with good control over average particle size, for powder, and grain size, for ceramics. This is a novel approach whose advantages can be then summarized as follows: (i) regarding synthesis, while realizing that zero-field processing of CCTO through either conventional solid-state reaction [30] or chemical route [32,37,38] did not allow producing nanopowder, processing under electric field and controlled current renders possible synthesis of a CCTO powder with an average particle size sensibly below $100 \mathrm{~nm}$ (scratched region in Fig. 7 inset); (ii) regarding sintering, high-density and fine-grained ceramics can be and were produced in a single running experiment approach by using electric field, starting from amorphous precursor powder, i.e., with no need of a prior, separate calcination step plus grinding and compaction before definitive heat treatment; (iii) both field-assisted synthesis and sintering processes are accomplished at time and furnace temperatures significantly lower than in conventional (zero-field) processing, opening as well a new window for exploring, as Fig. 7 suggests, preparation of submicron to nano-grained ceramic materials at a lower cost.

At this point, some comments have to be made. The natural difference we found here between flash sintering $\left(10 \mathrm{~V} \cdot \mathrm{cm}^{-1} \leqslant E \leqslant 40 \mathrm{~V} \cdot \mathrm{cm}^{-1}\right)$ and flash synthesis $\left(E \geqslant 60 \mathrm{~V} \cdot \mathrm{cm}^{-1}\right)$ is that the latter did not lead to densification, even when we allowed the current density limit to reach values higher than that of $J=22.0 \mathrm{~mA} \cdot \mathrm{mm}^{-2}$ considered in Fig. 2 (and Fig. S1(b) in the ESM), as we earlier commented with respect to 
Fig. 1(d). Because involving a chemical reaction of intermediate compounds to give the end phase (Fig. 3), the synthesis process should be here regarded as the nucleation of a new product at the contact surface between these intermediate phases. In the following, material transport should mainly occur from the surface of the original particles (surface as source the diffusing charges) to the forming and growing of nuclei, a mechanism which is expected to cause no important shrinkage [1]. The predictable changes in such a case are neck growth and eventually particle coarsening, as can be also concluded in this work when comparing, e.g., the microstructures shown in Figs. 6(d) $\left(E=200 \mathrm{~V} \cdot \mathrm{cm}^{-1}\right.$ and $\left.J=7.5 \mathrm{~mA} \cdot \mathrm{mm}^{-2}\right)$ versus $6(\mathrm{c})(E$ $=200 \mathrm{~V} \cdot \mathrm{cm}^{-1}$ and $J=22.0 \mathrm{~mA} \cdot \mathrm{mm}^{-2}$ ). In contrast, observation of a huge shrinkage (densifying mechanism) during flash sintering of the single-phase end-product powder means that the atomic transport process in that case originates from the volume of the particles (volume as source of the diffusing charges) and moves into the necks [1].

Irrespective of where each of these phenomena originates at the microstructural level, it is straightforward concluding from Fig. 2 (and Fig. S1 in the ESM), supported by the XRD data in Fig. 3, that development of the fast and flash events presented here involves enhanced charge diffusion because of field input. To get a further insight into this scenario, the sample temperature during conduction of such experiments must be also monitored, together with furnace temperature. This was done here by using a pyrometer operable at temperatures $T \geqslant 650{ }^{\circ} \mathrm{C}$, and Fig. 8 is an example of data showing the time evolution of furnace $\left(T_{\text {furn }}\right)$ versus pyrometer $\left(T_{\text {pyro }}\right)$ temperatures during processing of CCTO under 15 and $30 \mathrm{~V} \cdot \mathrm{cm}^{-1}$. Regarding flash sintering $\left(10 \mathrm{~V} \cdot \mathrm{cm}^{-1} \leqslant E\right.$ $\leqslant 40 \mathrm{~V} \cdot \mathrm{cm}^{-1}$ ), just to begin with, once the imposed current limit was reached, a stable temperature was as well reached during a steady-like state that we allowed to last $1 \mathrm{~min}$. The values of $T_{\text {pyro }}^{\mathrm{O} 3 \mathrm{~S}}$ and $T_{\text {furn }}^{\mathrm{O} 3 \mathrm{~S}}$ measured at that instant have also been included in Table 1 . A marked divergence between these two temperatures was in every case verified, with $T_{\text {pyro }}^{\mathrm{O} 3 \mathrm{~S}}>T_{\text {furn }}^{\mathrm{O} 3 \mathrm{~S}}$. This means that the increase in current-related power dissipation $(P=J \cdot E)$, i.e., Joule heating modulating the real sample temperature, is an important factor to be considered when trying to account for development of this phenomenon [39-42]. The data of power dissipation during materials processing are illustrated in Figs. S1(c) and S1(d) in the ESM. When the power supply was turned off, Fig. 8 also shows that both $T_{\text {pyro }}$ and $T_{\text {furn }}$ matched again (almost suddenly), as to be expected.

Regarding then the effect of sample temperature, flash sintering under, e.g., $E=30 \mathrm{~V} \cdot \mathrm{cm}^{-1}$ (point (e) in Fig. 2(a)) occurred at a furnace temperature $T_{\text {furn }}^{\mathrm{O} S}=$ $955^{\circ} \mathrm{C}$, while power dissipation input (of about $0.13 \mathrm{~W} \cdot \mathrm{mm}^{-3}$ ) led the specimen to reach a temperature $T_{\text {pyro }}^{\mathrm{O} S}=1037{ }^{\circ} \mathrm{C}$ (Fig. 8 and Table 1). We note that the final specimen density $\left(\rho_{\text {rel }}\right)$ was in this case $92 \% \mathrm{TD}$, while, in contrast, conventional (zero-field) sintering at a comparable temperature of $1030{ }^{\circ} \mathrm{C}$ ended with a sample showing only $77 \%$ TD after an identical annealing time of 1 min (Fig. 2(b) and Table 1). This result would suggest that the temperature-associated argument is alone not enough to justify a higher densification at $E=30 \mathrm{~V} \cdot \mathrm{cm}^{-1}$. From lattice expansion measurements, nevertheless, flash sintering temperatures reaching values comparable to those leading to high densification in conventional processing have been claimed [43,44]. Because related to surface measurements, it should be recognized that $T_{\text {pyro }}^{\mathrm{O} 3 \mathrm{~S}}$ may be lower than

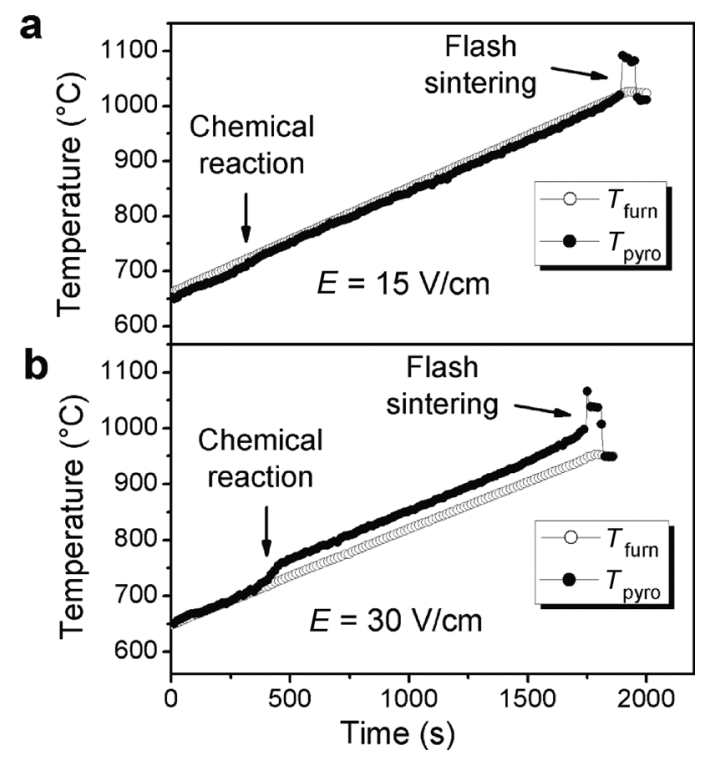

Fig. 8 Time evolution of the furnace versus pyrometry temperatures during fast $\mathrm{O} 3 \mathrm{~S}$ for powder processing under fields of (a) $E=15 \mathrm{~V} \cdot \mathrm{cm}^{-1}$ and (b) $E=30 \mathrm{~V} \cdot \mathrm{cm}^{-1}$. The temperature measured using the pyrometer $\left(T_{\text {pyro }}\right)$ is, in comparison, supposed to better represent the real specimen temperature. The temperature regions of chemical reaction and flash sintering occurrence are indicated in both cases. 
the real bulk temperature (although remaining certainly closer to this bulk value if compared with $T_{\text {furn }}^{\mathrm{O} S}$ ). This would justify why the higher densification for $E=$ $30 \mathrm{~V} \cdot \mathrm{cm}^{-1}$ in the comparison above, but does not straightforwardly account for (i) development of all the sintering-related process in mere seconds as well as (ii) the trend to sudden full densification.

In terms of cause-effect relationship, we believe that the factual question to be also or instead addressed is: why does the electric current suddenly rise in a non-linear way, indicating flash sintering triggering at a given instant during thermal processing in the presence of the field? Accordingly, sudden incidence of a defect generation process caused by the field as an important ingredient to be as well considered behind ignition of this phenomenon was earlier proposed [39]. Since then, several works have been aimed at finding answers to this open issue, still needing further experimental evidences from which to draw the concluding remarks regarding the major contributing mechanisms involved. The reader may find a description of possible mechanisms behind flash sintering in the review paper by Yu et al. [45], where postulation of electrochemical reduction is also registered, to be as well considered as a potential defects-based mechanism induced at the onset of flash. Recent reports suggesting validity of this idea of a parallel defect-related mechanism behind flash sintering may also be found elsewhere [46-48].

Concerning development of flash synthesis, applying here for $E \geqslant 60 \mathrm{~V} \cdot \mathrm{cm}^{-1}$, some values of $T_{\text {pyro }}$ were also representatively measured, the results of which are, e.g., 946 and $910{ }^{\circ} \mathrm{C}$ for flash under, respectively, 60 and $200 \mathrm{~V} \cdot \mathrm{cm}^{-1}$ (at $J=22.0 \mathrm{~mA} \cdot \mathrm{mm}^{-2}$ ). In the latter case (for which the time evolution of $T_{\text {pyro }}$ versus $T_{\text {furn }}$ is given in Fig. S3 in the ESM), reducing $J$ from 22.0 to $5.0 \mathrm{~mA} \cdot \mathrm{mm}^{-2}$ led to observing $T_{\text {pyro }}=750{ }^{\circ} \mathrm{C}$. These temperatures reveal high enough to encourage CCTO synthesis, expected to initiate when approaching $710{ }^{\circ} \mathrm{C}$ in conventional (zero-field) processing [36]. Nevertheless, as we remarked above, postulating here contribution from a field-promoted defect generation effect, acting together with Joule heating, appears also reasonable to account for manifestation of the whole phenomenon as a flash event. In particular, if $J$ at flash is allowed to significantly increase, Joule heating is naturally expected to enhance synergistically charge diffusion processes, the parallel result of which is observation of an increase in average particle size
(Figs. 6 and 7), as also reported elsewhere for average grain size in flash sintering experiments [20,49].

In the following, development of the electric field-assisted non-flash events is as well analysed. Regarding incidence of fast synthesis, applying at the shoulder-like anomaly in Fig. 2(a) (also verifiable in Figs. S1(a) and S1(c) in the ESM), difference between furnace and apparent sample (pyrometer) temperatures was from only 28 to $42{ }^{\circ} \mathrm{C}$ at $30 \mathrm{~V} \cdot \mathrm{cm}^{-1} \leqslant E \leqslant$ $40 \mathrm{~V} \cdot \mathrm{cm}^{-1}$ to undetectable at $10 \mathrm{~V} \cdot \mathrm{cm}^{-1} \leqslant E<$ $30 \mathrm{~V} \cdot \mathrm{cm}^{-1}$; these are the instances indicated as chemical reaction in Fig. 8. In any case, this shoulder-related process is in Figs. 2(a) and S1(a) and S1(c) in the ESM noted to develop at temperatures around $700{ }^{\circ} \mathrm{C}$, meaning also enough thermal energy to encourage CCTO synthesis [36]. Nevertheless, again, its occurrence in few minutes $(\leqslant 5 \mathrm{~min})$ contrasts with the fact that conventional (zero-field) synthesis of a second phase-free CCTO end-product requires heat treating identical Pechini-derived precursor powder for $2 \mathrm{~h}$ at about $800{ }^{\circ} \mathrm{C}$ [36]. In other words, fast synthesis should here involve some additional effect besides the expected influence from temperature.

The above observation also applies for crystallization, responsible for incidence of the current peak anomaly observed towards low temperatures in Fig. 2(a) inset. Pyrometry indicated that this process occurs at apparent sample temperatures $<650{ }^{\circ} \mathrm{C}$ (see, e.g., Fig. $\mathrm{S} 3$ in the ESM), and the furnace values scale below $500{ }^{\circ} \mathrm{C}$ for $E>210 \mathrm{~V} \cdot \mathrm{cm}^{-1}$, while crystallization is expected to take place at about $625{ }^{\circ} \mathrm{C}$ in conventional (zero-field) approach [36]. Apart from this, it should be observed, as we proposed in Ref. [36], that an increase in the rate at (and prematurity with) which this phenomenon develops during heat treatment is in fact also expected to be encouraged. This is because Gibbs free energy for formation of nuclei with critical size $\left(\Delta G_{\mathrm{C}}\right)$ under field input can be demonstrated to satisfy $[50,51]$ :

$$
\Delta G_{\mathrm{C}}=\frac{(16 / 3) \pi \gamma_{\mathrm{s}}^{3}}{\left[\left|\Delta G_{\mathrm{v}}\right|+(1 / 2) \varepsilon_{0}\left(K_{\mathrm{f}}-K_{\mathrm{i}}\right) E^{2}\right]^{2}}
$$

where $\Delta G_{\mathrm{V}}$ refers to the strain energy per unit volume, $\varepsilon_{0}$ is the permittivity of vacuum, $\gamma_{\mathrm{s}}$ the surface energy per unit area, and $K$ ( $\equiv K_{\text {real }}$ in this expression) the real part of dielectric constant. Accordingly, a decrease in $\Delta G_{\mathrm{C}}$ is predictable as long as the dielectric constant of the new medium $\left(K_{\mathrm{f}}\right)$ is higher than in the original medium $\left(K_{\mathrm{i}}\right)$. For the material processed under, e.g., $E$ 
$=30 \mathrm{~V} \cdot \mathrm{cm}^{-1}$, values of $K$ measured at $100 \mathrm{kHz}$ (towards which there was basically no $K$ dependency on measuring frequency; see data given later), on equally pressed powder, were $K_{(\mathrm{b})}=110$ and $K_{(\mathrm{a})}=85$, in connection with samples at points (b) and (a) in Fig. 2(a).

This reasoning of an expected enhanced rate (and prematurity) of process development also applies for the fast synthesis event presented in this report. This is because formation of a new phase from chemical reaction of the intermediate compounds involves as well crystallite nucleation and growth processes, and obeys equal thermodynamic approach for $\Delta G_{\mathrm{C}}$ (Eq. (3)); we found $K_{(\mathrm{c})}=143$ in relation to point (c) in Fig. 2(a). Overall, the observation is that increasing $E$ under $K_{\mathrm{f}}>K_{\mathrm{i}}$ has the positive effect of decreasing progressively $\Delta G_{\mathrm{C}}$, implying crystallization and synthesis processes predictable to occur more and more faster.

Back to flash synthesis, the argument of a decrease in $\Delta G_{\mathrm{C}}$ to account for acceleration of the synthesis process is also expected to apply. Nevertheless, its development in the form of a flash event should most likely involve, as discussed above, a field-generated defect avalanche-like process promoting a sudden increase in charge transport, i.e., electrical conductivity (and hence current density) and, consequently, sudden increase in Joule heating (modulating the real sample temperature) with also a direct impact again on electrical conductivity.

As earlier mentioned in this contribution, one reason for which CCTO and parent compounds have in recent years drawn considerable attention is the fact of showing a giant dielectric constant-like phenomenon, with $K_{\text {real }}$ values $\geqslant 10^{3}$ [24-27]. The values of dielectric constant we reported above are significantly lower because of dealing with porous samples. Figure 9(a) illustrates the $K_{\text {real }}$ data from CCTO after conventional as well as $\mathrm{O} 3 \mathrm{~S}$ processing, as a function of frequency. For data clarity, we chose to only show the spectra from $E=0$ versus $10,15,30 \mathrm{~V} \cdot \mathrm{cm}^{-1}$, enough to draw the following main conclusions. Overall, $K_{\text {real }}$ revealed almost frequency independent (only an unimportant trend to increase downwards low frequencies was observed), with values $\geqslant 10^{3}$ just as reported elsewhere [24-27]. This property involved capacitance values in the order of $10^{-10} \mathrm{~F}$, meaning (for measurements conducted here on small, millimeter-sized samples) to basically reflect the material response, i.e., with no electrode polarization-like contribution [34]. $K_{\text {real }}$ was sensibly higher in the high-density, field-sintered samples $(92 \%-98 \%$ TD) than in the porous,

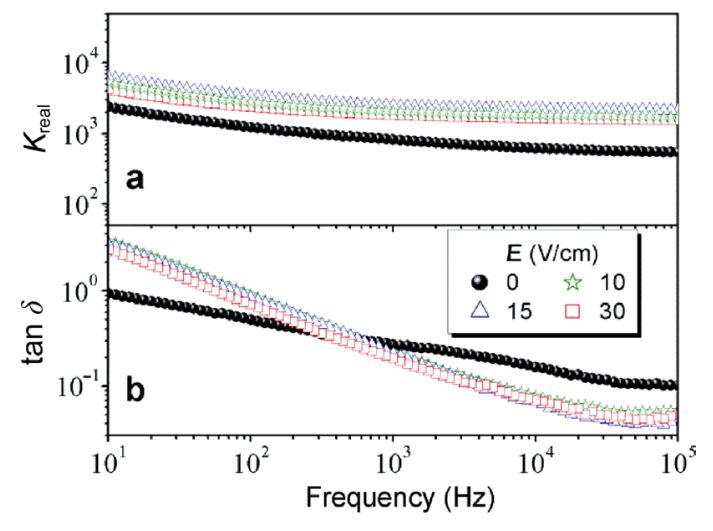

Fig. 9 Frequency dependence of (a) real part of dielectric constant $\left(K_{\text {real }}\right)$ and (b) dielectric loss $(\tan \delta)$ measured at room temperature for CCTO samples processed under $E=$ $0,10,15$, and $30 \mathrm{~V} \cdot \mathrm{cm}^{-1}$.

conventionally-sintered body (77\% $\quad$ TD), and is accordingly expected to be even lower in much more porous specimens, as in the case of the $K_{(\mathrm{a})}, K_{(\mathrm{b})}$, and $K_{\text {(c) }}$ values we reported above for the as-pressed, non-sintered powder.

Figure 9(b) now refers to the dielectric loss data from these materials, appraised as $\tan \delta\left(\equiv K_{\text {imag }} / K_{\text {real }}\right)$. Even with $K_{\text {real }}$ revealing almost frequency independent (Fig. 9(a)), an increase in dielectric losses is observed downwards low frequencies, an effect to be then mainly ascribed to direct current (DC) conductivity contribution to dielectric losses. This contribution reveals less important for the conventionally-sintered sample, most likely because, besides the deleterious effect of porosity limiting electrical conduction, thermally-induced development of defects leading to observation of a semiconducting-like CCTO bulk $[32,52]$ should in this case be still incomplete.

Notice in Fig. 9(b) that $\tan \delta$ is almost frequency independent towards the highest frequencies, where the genuine dielectric response (free of not only electrode polarization but also DC conductivity contributions) from such materials can be then assessed. This is the frequency region we considered to be of direct interest to compare among samples. Observe that the field-sintered bodies show lower dielectric losses $(\tan \delta \leqslant 0.05)$ when compared to the conventionally-sintered specimen $(\tan \delta \approx 0.10)$. This scenario of a high dielectric constant combined with relatively low dielectric losses for the field-sintered materials is as attractive as has been also found for laser-sintered CCTO specimens where extremely high sintering rates, as contrasted to conventional sintering, play an important role [32]. In 
general, material processing parameters, namely, sintering temperature and rate, plus annealing time, have been all shown to strongly modulate the defect chemistry and, hence, degree of defect-mediated semiconductivity and dielectric response observed in ACTO $(\mathrm{A}=\mathrm{Ca}$, $\mathrm{Bi}_{2 / 3}$, etc.)-type compounds $[22,32,52,53]$. This could be the main clue for the design of processing protocols that may help optimizing the physico-chemical properties of such materials and materializing, in future, their application in electro-electronic devices.

For contextualization purpose, we should mention that most results presented in this report, together with those earlier published in Ref. [36] on flash synthesis of nanopowders, are part of L. M. Jesus' Ph.D. thesis defended in 2016 [54]. This pioneering work on electric field-assisted ultrafast processing of materials in a one-step approach, starting from either amorphous or multi-phase precursors, is currently being extended (exploring achievability conditions, included) to other simple and complex compounds, and the results will be the content of forthcoming contributions.

\section{Conclusions}

We have demonstrated that processing, say, synthesis and sintering of materials can be both remarkably accelerated by using electric fields. Starting here from amorphous CCTO powder, for instance, this was shown to experience crystallization through intermediate phases, followed by either flash synthesis, at high fields, or fast one-step synthesis plus sintering (O3S), at low fields, in a single running experiment approach. These events develop at furnace temperatures and dwell time significantly reduced, the consequence of which is quick material processing, with good control over particle (for end powder) and grain (for ceramics) coarsening. Concretely, high-quality CCTO nanopowder was here produced where zero-field processing methods fail, as well as fine-grained eletroceramics showing high dielectric constant $\left(\geqslant 10^{3}\right)$ coupled with relatively low dielectric losses $(\tan \delta \leqslant 0.05)$. With examples provided on CCTO and BCTO (in the ESM), this work has also shown, accordingly, that monitoring the electric current of materials during processing under field input can be used as an efficient and cost-effective way to detecting occurrence of crystallization and/or chemical reactions, the events of which produce detectable current anomalies. Where such physico- chemical events do not apply, just as we presented here for single-phase CCTO and BCTO end powders, no current anomaly manifested, except when flash sintering came into play. In summary, we consider that simplicity of the approaches presented in this work opens a new development window that deserves great attention for detailed explorations on (i) ultrafast synthesis and (ii) fast synthesis plus sintering of materials, in a single running experiment approach, no matter if starting from a multi-phase powder (mixture of metal oxides) or even an amorphous precursor powder, as we have here shown.

\section{Acknowledgements}

This work was partly supported by the Coordenação de Aperfeiçoamento de Pessoal de Nível Superior - Brasil (CAPES) - Finance Code 001, through Grant Nos. BEX 3276/14-7 and BEX 9291/13-0. J.-C. M'Peko devised the work. L. M. Jesus and R. S. Silva were responsible for chemical synthesis. L. M. Jesus conducted the field-assisted processing experiments, plus material characterization (XRD, SEM, and dielectric measurements) under J.-C. M'Peko's supervision. J.-C. M'Peko wrote the first draft of the manuscript, and all present authors participated in manuscript revision, followed by submission approval. L. M. Jesus and J.-C. M'Peko are profoundly grateful to Prof. R. Raj (at CU Boulder, USA) for introduction to flash sintering experiments and for allowing collection of some data presented here. S. K. Jha and J.-M. Lebrun are also thanked for assistance in some of the conducted flash experiments, as well as B. E. Francisco for help with some of the XRD measurements carried out.

\section{Electronic Supplementary Material}

Supplementary material is available in the online version of this article at https://doi.org/10.1007/s40145-018-0313-1.

\section{References}

[1] Chiang Y-M, Birnie III DP, Kingery WD. Physical Ceramics: Principles for Ceramic Science and Engineering. John Wiley \& Sons, Inc., 1997.

[2] Polarz S, Roy A, Lehmann M, et al. Structureproperty-function relationships in nanoscale oxide sensors: A case study based on zinc oxide. Adv Funct Mater 2007, 17: 1385-1391.

[3] Wang K, Yao F-Z, Jo W, et al. Temperature-insensitive 
(K,Na) $\mathrm{NbO}_{3}$-based lead-free piezoactuator ceramics. $A d v$ Funct Mater 2013, 23: 4079-4086.

[4] MacAry LS, Kahn ML, Estournès C, et al. Size effect on properties of varistors made from zinc oxide nanoparticles through low temperature spark plasma sintering. Adv Funct Mater 2009, 19: 1775-1783.

[5] Chen I-W, Wang X-H. Sintering dense nanocrystalline ceramics without final-stage grain growth. Nature 2000, 404: $168-171$.

[6] Cameron CP, Raj R. Grain-growth transition during sintering of colloidally prepared alumina powder compacts. J Am Ceram Soc 1988, 71: 1031-1035.

[7] Zhan G-D, Kuntz JD, Wan JL, et al. Single-wall carbon nanotubes as attractive toughening agents in alumina-based nanocomposites. Nat Mater 2003, 2: 38-42.

[8] Raj R, Cologna M, Francis JSC. Influence of externally imposed and internally generated electrical fields on grain growth, diffusional creep, sintering and related phenomena in ceramics. J Am Ceram Soc 2011, 94: 1941-1965.

[9] Lu K. Sintering of nanoceramics. Int Mater Rev 2008, 53: 21-38.

[10] He XL, Ye F, Zhang HJ, et al. Study on microstructure and thermal conductivity of spark plasma sintering AIN ceramics. Mater Des 2010, 31: 4110-4115.

[11] Nekouee KA, Khosroshahi RA. Preparation and characterization of $\beta$-SiAlON/TiN nanocomposites sintered by spark plasma sintering and pressureless sintering. Mater Des 2016, 112: 419-428.

[12] Samara GA. Pressure and temperature dependences of the dielectric properties of the perovskites $\mathrm{BaTiO}_{3}$ and $\mathrm{SrTiO}_{3}$. Phys Rev 1966, 151: 378-386.

[13] Malinowski M, Łukaszewicz K, Åsbrink S. The influence of high hydrostatic pressure on lattice parameters of a single crystal of $\mathrm{BaTiO}_{3}$. J Appl Cryst 1986, 19: 7-9.

[14] Cologna M, Rashkova B, Raj R. Flash sintering of nanograin zirconia in $<5 \mathrm{~s}$ at $850^{\circ} \mathrm{C}$. J Am Ceram Soc 2010, 93: 3556-3559.

[15] M'Peko J-C, Francis JSC, Raj R. Impedance spectroscopy and dielectric properties of flash versus conventionally sintered yttria-doped zirconia electroceramics viewed at the microstructural level. J Am Ceram Soc 2013, 96: 3760-3767.

[16] Prette ALG, Cologna M, Sglavo VM, et al. Flash-sintering of $\mathrm{Co}_{2} \mathrm{MnO}_{4}$ spinel for solid oxide fuel cell applications. $J$ Power Sources 2011, 196: 2061-2065.

[17] Cologna M, Francis JSC, Raj R. Field assisted and flash sintering of alumina and its relationship to conductivity and MgO-doping. J Eur Ceram Soc 2011, 31: 2827-2837.

[18] Muccillo R, Muccillo ENS, Kleitz M. Densification and enhancement of the grain boundary conductivity of gadolinium-doped barium cerate by ultra fast flash grain welding. J Eur Ceram Soc 2012, 32: 2311-2316.

[19] Hao XM, Liu YJ, Wang ZH, et al. A novel sintering method to obtain fully dense gadolinia doped ceria by applying a direct current. J Power Sources 2012, 210: 86-91.
[20] M'Peko J-C, Francis JSC, Raj R. Field-assisted sintering of undoped $\mathrm{BaTiO}_{3}$ : Microstructure evolution and dielectric permittivity. J Eur Ceram Soc 2014, 34: 3655-3660.

[21] Jha SK, Raj R. The effect of electric field on sintering and electrical conductivity of titania. J Am Ceram Soc 2014, 97: 527-534.

[22] Jesus LM, Silva RS, Raj R, et al. Electric field-assisted flash sintering of $\mathrm{CaCu}_{3} \mathrm{Ti}_{4} \mathrm{O}_{12}$ : Microstructure characteristics and dielectric properties. $J$ Alloys Compd 2016, 682: 753-758.

[23] Su X, Bai G, Zhang J, et al. Preparation and flash sintering of $\mathrm{MgTiO}_{3}$ nanopowders obtained by the polyacrylamide gel method. Appl Surf Sci 2018, 442: 12-19.

[24] Subramanian MA, Li D, Duan N, et al. High dielectric constant in $\mathrm{ACu}_{3} \mathrm{Ti}_{4} \mathrm{O}_{12}$ and $\mathrm{ACu}_{3} \mathrm{Ti}_{3} \mathrm{FeO}_{12}$ phases. $J$ Solid State Chem 2000, 151: 323-325.

[25] Li J, Subramanian MA, Rosenfeld HD, et al. Clues to the giant dielectric constant of $\mathrm{CaCu}_{3} \mathrm{Ti}_{4} \mathrm{O}_{12}$ in the defect structure of " $\mathrm{SrCu}_{3} \mathrm{Ti}_{4} \mathrm{O}_{12}$ ". Chem Mater 2004, 16: 5223-5225.

[26] Sinclair DC, Adams TB, Morrison FD, et al. $\mathrm{CaCu}_{3} \mathrm{Ti}_{4} \mathrm{O}_{12}$ : One-step internal barrier layer capacitor. Appl Phys Lett 2002, 80: 2153-2155.

[27] Adams TB, Sinclair DC, West AR. Giant barrier layer capacitance effects in $\mathrm{CaCu}_{3} \mathrm{Ti}_{4} \mathrm{O}_{12}$ ceramics. Adv Mater 2002, 14: 1321-1323.

[28] Chung S-Y, Kim I-D, Kang S-JL. Strong nonlinear current-voltage behaviour in perovskite-derivative calcium copper titanate. Nat Mater 2004, 3: 774-778.

[29] Schmidt R, Stennett MC, Hyatt NC, et al. Effects of sintering temperature on the internal barrier layer capacitor (IBLC) structure in $\mathrm{CaCu}_{3} \mathrm{Ti}_{4} \mathrm{O}_{12}$ (CCTO) ceramics. J Eur Ceram Soc 2012, 32: 3313-3323.

[30] Löhnert R, Schmidt R, Töpfer J. Effect of sintering conditions on microstructure and dielectric properties of $\mathrm{CaCu}_{3} \mathrm{Ti}_{4} \mathrm{O}_{12}$ (CCTO) ceramics. $J$ Electroceram 2015, 34: 241-248.

[31] Pechini MP. U.S. Patent No. 3,330.697. 1967.

[32] Jesus LM, Santos JCA, Sampaio DV, et al. Polymeric synthesis and conventional versus laser sintering of $\mathrm{CaCu}_{3} \mathrm{Ti}_{4} \mathrm{O}_{12}$ electroceramics: (Micro)structures, phase development and dielectric properties. $J$ Alloys Compd 2016, 654: 482-490.

[33] ASTM E1382-97. Standard Test Methods for Determining Average Grain Size Using Semiautomatic and Automatic Image Analysis. ASTM International, West Conshohocken, PA, 1997.

[34] García-Sánchez MF, M'Peko J-C, Ruiz-Salvador AR, et al. An elementary picture of dielectric spectroscopy in solids: Physical basis. J Chem Educ 2003, 80: 1062-1073.

[35] Bochu B, Deschizeaux MN, Joubert JC, et al. Synthèse et caractérisation d'une série de titanates pérowskites isotypes de $\left[\mathrm{CaCu}_{3}\right]\left(\mathrm{Mn}_{4}\right) \mathrm{O}_{12}$. J Solid State Chem 1979, 29: 291-298.

[36] Jesus LM, Silva RS, Raj R, et al. Electric field-assisted ultrafast synthesis of nanopowders: A novel and cost-efficient approach. RSC Adv 2016, 6: 107208-107213. 
[37] Liu JJ, Sui YC, Duan C-G, et al. $\mathrm{CaCu}_{3} \mathrm{Ti}_{4} \mathrm{O}_{12}$ : Low-temperature synthesis by pyrolysis of an organic solution. Chem Mater 2006, 18: 3878-3882.

[38] Liu JJ, Smith RW, Mei W-N. Synthesis of the giant dielectric constant material $\mathrm{CaCu}_{3} \mathrm{Ti}_{4} \mathrm{O}_{12}$ by wet-chemistry methods. Chem Mater 2007, 19: 6020-6024.

[39] Raj R. Joule heating during flash-sintering. J Eur Ceram Soc 2012, 32: 2293-2301.

[40] Todd RI, Zapata-Solvas E, Bonilla RS, et al. Electrical characteristics of flash sintering: Thermal runaway of Joule heating. J Eur Ceram Soc 2015, 35: 1865-1877.

[41] Zhang YY, Jung J-I, Luo J. Thermal runaway, flash sintering and asymmetrical microstructural development of $\mathrm{ZnO}$ and $\mathrm{ZnO}-\mathrm{Bi}_{2} \mathrm{O}_{3}$ under direct currents. Acta Mater 2015, 94: 87-100.

[42] Du YX, Stevenson AJ, Vernat D, et al. Estimating Joule heating and ionic conductivity during flash sintering of 8YSZ. J Eur Ceram Soc 2016, 36: 749-759.

[43] Charalambous H, Jha SK, Lay RT, et al. Investigation of temperature approximation methods during flash sintering of ZnO. Ceram Int 2018, 44: 6162-6169.

[44] Charalambous $\mathrm{H}$, Jha SK, Phuah XL, et al. In situ measurement of temperature and reduction of rutile titania using energy dispersive X-ray diffraction. J Eur Ceram Soc 2018, 38: 5503-5511.

[45] Yu M, Grasso S, McKinnon R, et al. Review of flash sintering: Materials, mechanisms and modelling. Adv Appl Ceram 2017, 116: 24-60.

[46] Gao Y, Liu FZ, Liu DG, et al. Electrical-field induced nonlinear conductive behavior in dense zirconia ceramic. $J$ Mater Sci Technol 2017, 33: 897-900.

[47] Liu DG, Cao YJ, Liu JL, et al. Effect of oxygen partial pressure on temperature for onset of flash sintering $3 \mathrm{YSZ} . J$ Eur Ceram Soc 2018, 38: 817-820.

[48] Su XH, Bai G, Jia YJ, et al. Flash sintering of lead zirconate titanate (PZT) ceramics: Influence of electrical field and current limit on densification and grain growth. $J$ Eur Ceram Soc 2018, 38: 3489-3497.
[49] Francis JSC, Raj R. Influence of the field and the current limit on flash sintering at isothermal furnace temperatures. $J$ Am Ceram Soc 2013, 96: 2754-2758.

[50] Liu W, Liang KM, Zheng YK, et al. The effect of an electric field on the phase separation of glasses. $J$ Phys $D$ : Appl Phys 1997, 30: 3366-3370.

[51] Naik KS, Sglavo VM, Raj R. Flash sintering as a nucleation phenomenon and a model thereof. J Eur Ceram Soc 2014, 34: 4063-4067.

[52] Costa SIR, Li M, Frade JR, et al. Modulus spectroscopy of $\mathrm{CaCu}_{3} \mathrm{Ti}_{4} \mathrm{O}_{12}$ ceramics: Clues to the internal barrier layer capacitance mechanism. RSC Adv 2013, 3: 7030-7036.

[53] Jesus LM, Barbosa LB, Ardila DR, et al. Effect of conventional and laser sintering on the (micro)structural and dielectric properties of $\mathrm{Bi}_{2 / 3} \mathrm{Cu}_{3} \mathrm{Ti}_{4} \mathrm{O}_{12}$ synthesized through a polymeric precursor route. J Alloys Compd 2018, 735: 2384-2394.

[54] Jesus LM. Conventional, laser and electric field-assisted processing of $\mathrm{ACu}_{3} \mathrm{Ti}_{4} \mathrm{O}_{12}\left(\mathrm{~A}=\mathrm{Ca}, \mathrm{Bi}_{2 / 3}\right)$ electroceramics: (Micro)structure and (di)electrical properties. Ph.D. Thesis. São Carlos Institute of Physics, University of São Paulo (USP), Brazil, 2016.

Open Access This article is licensed under a Creative Commons Attribution 4.0 International License, which permits use, sharing, adaptation, distribution and reproduction in any medium or format, as long as you give appropriate credit to the original author(s) and the source, provide a link to the Creative Commons licence, and indicate if changes were made.

The images or other third party material in this article are included in the article's Creative Commons licence, unless indicated otherwise in a credit line to the material. If material is not included in the article's Creative Commons licence and your intended use is not permitted by statutory regulation or exceeds the permitted use, you will need to obtain permission directly from the copyright holder.

To view a copy of this licence, visit http://creativecommons. org/licenses/by/4.0/. 